\title{
Low temperature heat treatments on Ti-15Zr-xMo alloys
}

\author{
Caio Castanho Xavier a, b, *, Diego Rafael Nespeque Correa ${ }^{\text {a, b }}$, Carlos Roberto Grandini a, b, \\ Luís Augusto Rocha a, b, c
}

a UNESP - Univ Estadual Paulista, Faculdade de Ciências de Bauru, Bauru, SP, Brazil

${ }^{\mathrm{b}}$ IBTN/Br, Brazilian Branch of the Institute of Biomaterials, Tribocorrosion and Nanomedicine, Bauru, SP, Brazil

${ }^{\mathrm{c}}$ MEMS-UMinho, Center MicroElectroMechanical Systems, Universidade do Minho, Campus de Azurém, Guimarães, Portugal

\section{A R T I C L E I N F O}

\section{Article history:}

Received 14 February 2017

Received in revised form

7 August 2017

Accepted 9 August 2017

Available online 12 August 2017

\section{Keywords:}

Titanium

Alloys

Heat treatment

Biomaterials

\begin{abstract}
A B S T R A C T
This paper regards the study of the effect of heat treatments on the microstructure and microhardness of Ti-15Zr-xMo alloys aimed to biomedical applications. The alloys were melted in an arc-furnace, with four different compositions in order to obtain samples with $\alpha^{\prime}, \alpha^{\prime}+\beta$ and $\beta$ phase microstructures. The as-cast alloys exhibited a full lamellar structure for the Ti-15Zr, a bimodal structure composed by $\beta$ phase grains along with an $\alpha$ phase acicular structure at the grain boundaries for the Ti-15Zr-5Mo, predominant $\beta$ phase for the Ti-15Zr-10Mo and only $\beta$ phase for the Ti-15Zr-15Mo. Results showed that both microstructure and mechanical properties of the studied alloys can be tailored by relatively low temperature heat treatments, as they resulted in the growth of the $\alpha^{\prime}$ phase in all alloys. The formation of $\alpha^{\prime}$ phase resulted in a decrease in the microhardness of the alloys.
\end{abstract}

() 2017 Elsevier B.V. All rights reserved.

\section{Introduction}

Titanium and its alloys have been already consolidated as biomaterials, due to their excellent properties regarding corrosion resistance, Young's modulus, density and biocompatibility. Also, with the increase in the life expectancy and the growing age of general population, the research for new biomaterials and/or the improvement in its performance is utter required [1-3].

In equilibrium conditions, upon heating, titanium undergo an allotropic transformation at $882.5{ }^{\circ} \mathrm{C}$ where its microstructure shifts from a hexagonal compact (hcp) structure, also called $\alpha$ phase, to a body centered cubic (bcc) structure, called $\beta$ phase ( $\beta$ transus transformation) [2-4]. This allotropic transformation provides a possibility for controlling the mechanical properties of the alloy, through heat treatment [4]. The $\beta$ transus, also bears great influence from the alloying elements added to pure titanium, which can be categorized as $\alpha$-stabilizers and $\beta$-stabilizers, depending on their effects on the increase of the stability range of $\alpha$ and $\beta$ phases, respectively. As well, through heat or thermomechanical treatments, metastable structures may appear $[5,6]$. The orthorhombic phase $\left(\alpha^{\prime \prime}\right)$ is characterized by a fine acicular structure and can be

\footnotetext{
* Corresponding author. UNESP - Univ Estadual Paulista, Faculdade de Ciências de Bauru, Bauru, SP, Brazil.

E-mail address: caiocast@fc.unesp.br (C.C. Xavier).
}

obtained with high cooling rates or being mechanically induced $[7,8]$. The addition of a $\beta$-stabilizer element, such as molybdenum, may provide better mechanical properties, of interest for biomedical applications, namely a lower elastic modulus $[9,10]$.

Shi et al. [11], studied the evolution of the microstructure and tensile properties of an $\alpha+\beta$ Ti alloy (Ti-47Zr-5Al-3V) as a function of cold deformation and heat treatment. The processing route consisted of a cold deformation followed by $\alpha / \beta$ and $\beta$ thermal annealing at $650-800^{\circ} \mathrm{C} / 1 \mathrm{~h}$ and air cooling to room temperature, with a subsequent aging treatment at $450^{\circ} \mathrm{C} / 2 \mathrm{~h}$ followed by air cooling. The increase of the annealing temperature resulted in a greater amount of $\alpha$ phase, while aging leads to a further precipitation of this fine needle like structure.

Qin et al. [12], in their study of the formation of a bimodal microstructure of a $\mathrm{Ti}-5 \mathrm{Al}-5 \mathrm{~V}-5 \mathrm{Mo}-3 \mathrm{Cr}-0.4 \mathrm{Si}$ (Ti-5553s) alloy, correlated the $\alpha$ phase precipitation inside $\beta$ grains and at its boundaries with the aging temperature $\left(600^{\circ} \mathrm{C}, 700{ }^{\circ} \mathrm{C}, 750{ }^{\circ} \mathrm{C}\right.$ and $800{ }^{\circ} \mathrm{C} / 8 \mathrm{~h}$ followed by water quenching). It was observed that the volume fraction of $\alpha$ phase increased with the decrease in the aging temperature.

Investigating an $\alpha+\beta$ Ti-6Al-4V alloy, Wu et al. [13], carried out heat treatments in the temperature range from 300 to $1020^{\circ} \mathrm{C}$, followed by water quenching. It was reported that up to $500{ }^{\circ} \mathrm{C}$, an acicular morphology is noticeable resulting in the increase of the microhardness. Above this temperature, they observed a decrease 
in the microhardness of the alloy due to the increase of platelets of $\alpha$ phase and $\beta$ grains until $900{ }^{\circ} \mathrm{C}$. From 900 to $1020^{\circ} \mathrm{C}$, there is a fully equiaxed $\beta$ grains formation with an increase of the microhardness.

As referred, different processing routes, i.e. heat treatments, mechanical or thermomechanical processes, have a great influence in the microstructure and mechanical properties of Ti alloys.

In summary, $\alpha+\beta$ type titanium alloys generally present good mechanical properties with different processing routes. The heat treatment has great impact on the microstructure and mechanical properties, providing lamellar, equiaxed or bimodal microstructures which offer alternative mechanical properties [11-14]. This paper proposes, for the first time, to investigate low temperature heat treatments and its effects concerning the $\alpha$ phase precipitation on the microstructure and microhardness (HV) of Ti-15Zr-xMo alloys system, with potential for biomaterial applications.

\section{Experimental procedure}

The alloys were melted in an arc-furnace, with four different compositions: Ti-15Zr, Ti-15Zr-5Mo, Ti-15Zr-10Mo and Ti-15Zr$15 \mathrm{Mo}$, allowing samples with $\alpha, \alpha+\beta$ and $\beta$ phase microstructures to be obtained. The furnace was composed of a non-consumable tungsten electrode and a water-cooled copper crucible, where the raw materials could be melted within an argon atmosphere. After melting, the chemical composition of the samples was obtained by Energy Dispersive X-Ray (EDX) analysis, using an EVO LS-15 Carl Zeiss microscope with Oxford Inca $\mathrm{X}$-act probe. The heat treatments were performed at a relatively low temperature $\left(600{ }^{\circ} \mathrm{C}\right)$ with holding times of $6 \mathrm{~h}, 12 \mathrm{~h}$ and $24 \mathrm{~h}$. This temperature was chosen because it is below $\beta$-transus and allows growth for the acicular $\alpha^{\prime}$ phase microstructure in the alloy. The heat treatment conditions are shown in Table 1. The heat-treated samples were characterized in terms of their microstructure, through optical microscopy, x-ray diffraction (XRD) with Rietveld's Refinement and Vickers microhardness.

Also, from previous work of our group with the same alloy composition, the Young modulus for the as-cast condition is presented in Table 2 [15].

The microstructural analysis was performed using an Olympus BX51M microscope. Samples were previously prepared by standard grinding with $\mathrm{SiC}$ waterproof papers until \#1200 grit followed by a final polishing in a colloidal alumina suspension. Before the microstructural analysis in the optical microscope, the samples were chemically etched with $\mathrm{H}_{2} \mathrm{O}, \mathrm{HNO}_{3}$ and $\mathrm{HF}$ in the 80:15:5 proportion.

Table 1

Heat treatment conditions.

\begin{tabular}{llll}
\hline Temperature & Time & Cooling rate & Reference of sample \\
\hline $600{ }^{\circ} \mathrm{C}$ & $6 \mathrm{~h}$ & $10{ }^{\circ} \mathrm{C} / \mathrm{min}$ & $600^{\circ} \mathrm{C} / 6 \mathrm{~h} / 10^{\circ} \mathrm{C} \cdot \mathrm{min}^{-1}$ \\
& $12 \mathrm{~h}$ & & $600^{\circ} \mathrm{C} / 12 \mathrm{~h} / 10^{\circ} \mathrm{C} \cdot \mathrm{min}^{-1}$ \\
& $24 \mathrm{~h}$ & & $600^{\circ} \mathrm{C} / 24 \mathrm{~h} / 10^{\circ} \mathrm{C} \cdot \mathrm{min}^{-1}$ \\
\hline
\end{tabular}

Table 2

Young Modulus values for the as cast condition alloys from previous work [15].

\begin{tabular}{ll}
\hline Alloy & Young Modulus (GPa) \\
\hline Ti-15Zr & 97 \\
Ti-15Zr-5Mo & 98 \\
Ti-15Zr-10Mo & 82 \\
Ti-15Zr-15Mo & 75 \\
\hline
\end{tabular}

Table 3

EDX chemical analysis for the Ti-15Zr-xMo alloy composition.

\begin{tabular}{llll}
\hline Alloy & Ti (wt.\%) & Zr (wt.\%) & Mo (wt.\%) \\
\hline Ti-15Zr & $84.17 \pm 0.23$ & $15.83 \pm 0.23$ & - \\
Ti-15Zr-5Mo & $79.05 \pm 0.20$ & $15.67 \pm 0.17$ & $5.28 \pm 0.03$ \\
Ti-15Zr-10Mo & $73.61 \pm 0.16$ & $15.89 \pm 0.11$ & $10.50 \pm 0.16$ \\
Ti-15Zr-15Mo & $68.51 \pm 0.24$ & $15.81 \pm 0.16$ & $15.68 \pm 0.12$ \\
\hline
\end{tabular}

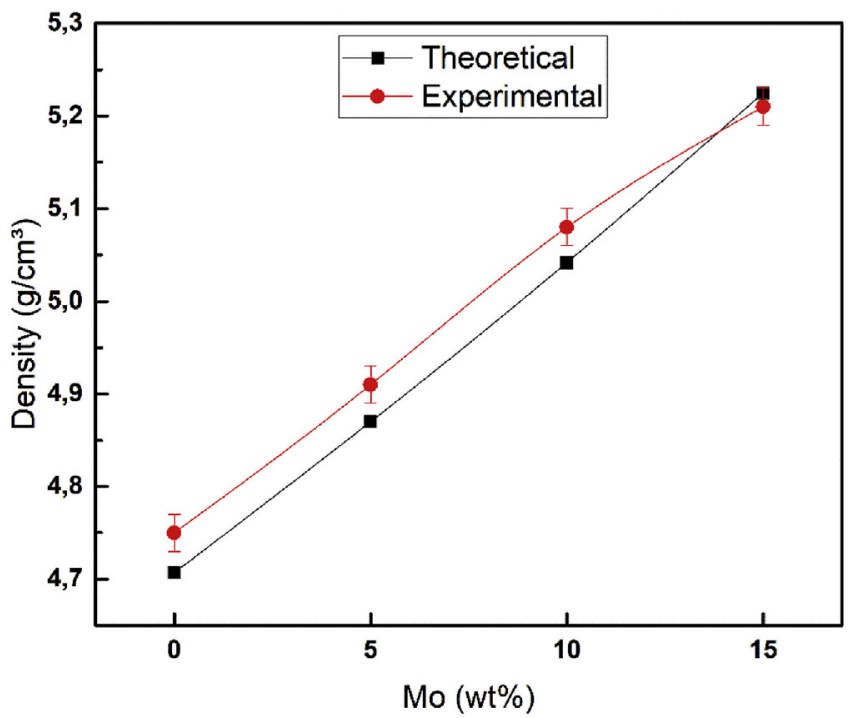

Fig. 1. Density for the as-cast Ti-15Zr-xMo alloys.

The XRD measurements were carried out in a Rigaku model D/ Max 2100/PC diffractometer, using $\mathrm{Cu}-\mathrm{K} \alpha$ radiation (1.544 $\AA$ wavelength) and the data were collected with $0.02^{\circ}$ steps, through $10^{\circ}$ and $100^{\circ}$ range, with $3.2 \mathrm{~s}$ of fixed time.

Vickers microhardness measurements were done in microhardness tester Shimadzu HMV-2 model, with 20 indentations, 60s

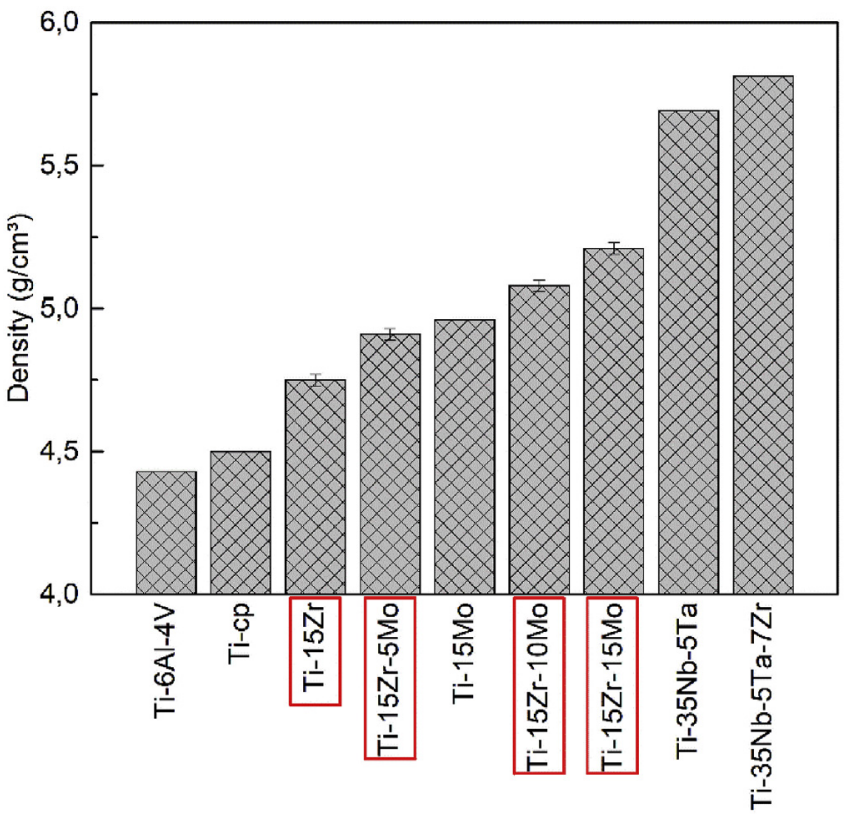

Fig. 2. Density for the as-cast Ti-15Zr-xMo alloys in comparison with others in literature. 


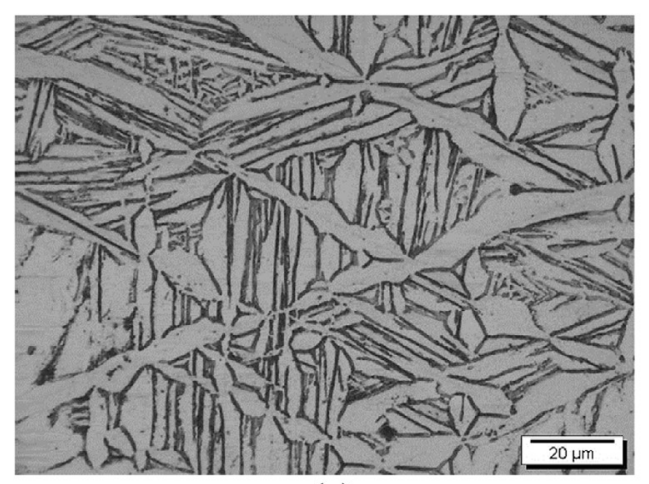

(a)

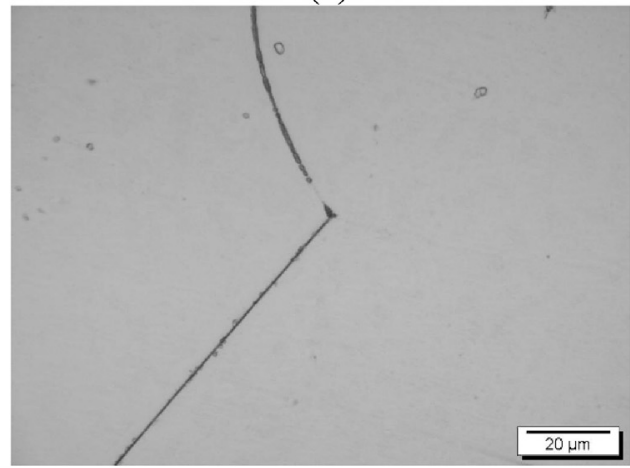

(c)

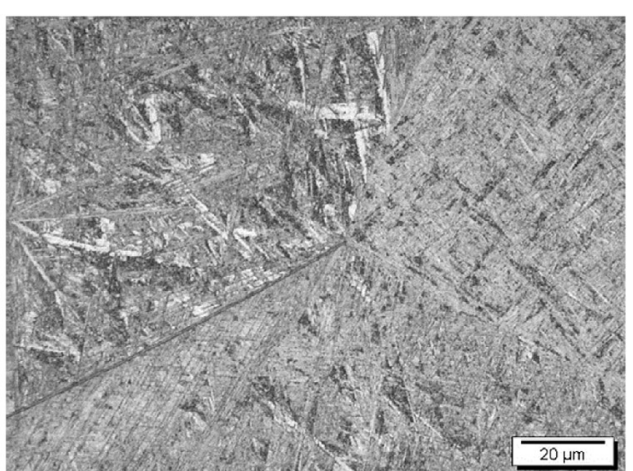

(b)

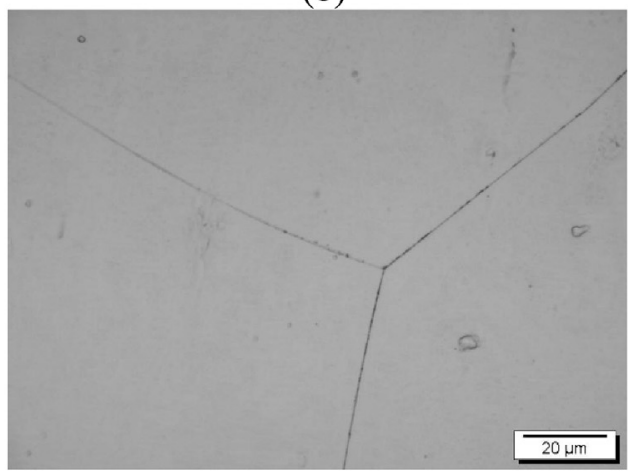

(d)

Fig. 3. Optical micrographs of the as-cast Ti-15Zr-xMo alloys: (a) Ti-15Zr; (b) Ti-15Zr-5Mo; (c) Ti-15Zr-10Mo; (d) Ti-15Zr-15Mo.

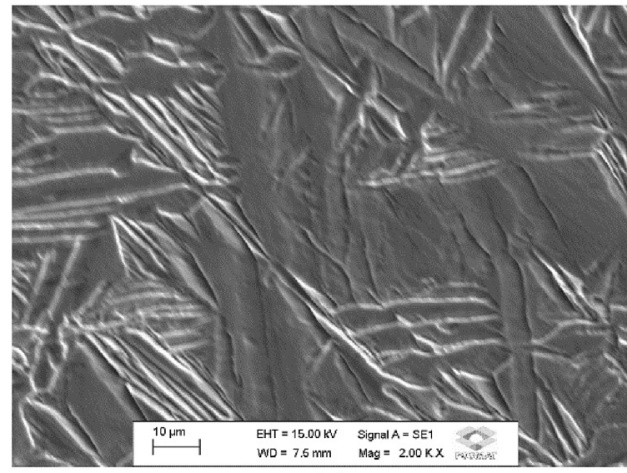

(a)

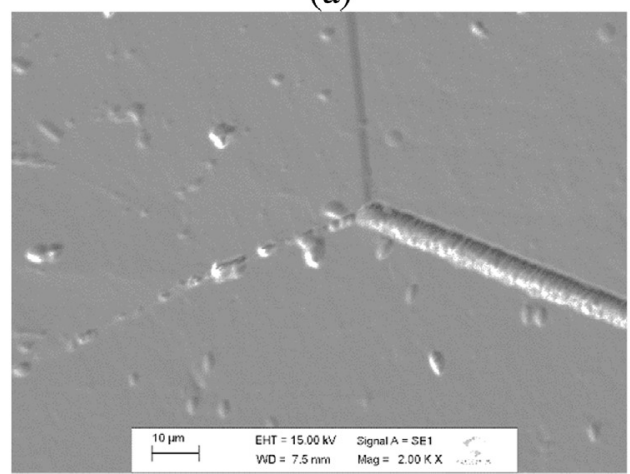

(c)

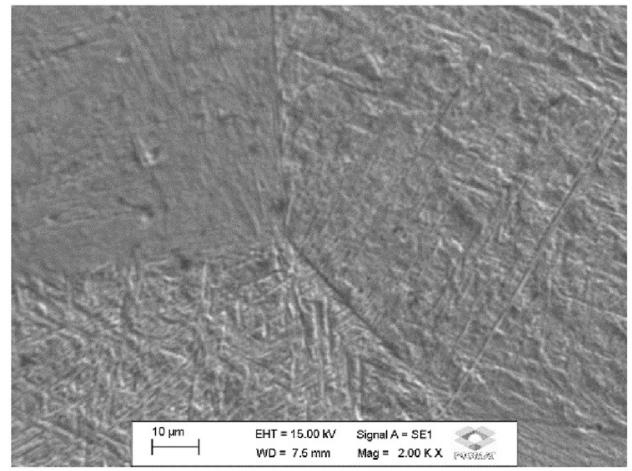

(b)

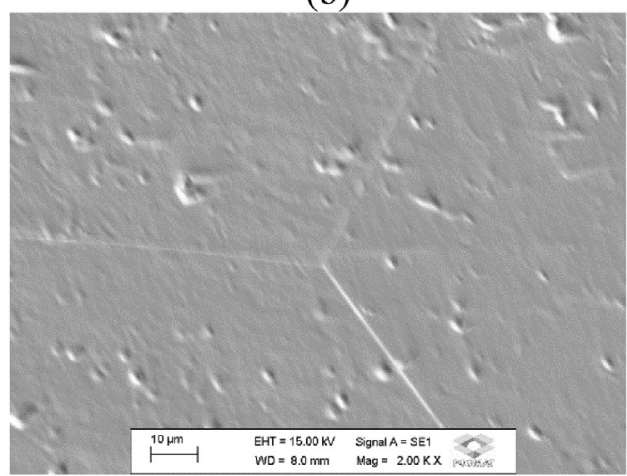

(d)

Fig. 4. SEM analysis of the as-cast Ti-15Zr-xMo alloys: (a) Ti-15Zr; (b) Ti-15Zr-5Mo; (c) Ti-15Zr-10Mo; (d) Ti-15Zr-15Mo. 
each, and a load of $250 \mathrm{~g}$. Also, HRC hardness measurements were carried out in an Officine Galileo durometer, with a standard load of $150 \mathrm{~kg}$.

Density was evaluated through Archimedes' principle in an Ohaus analytical balance, with $0.0001 \mathrm{~g}$ precision.

\section{Results and discussions}

\subsection{Characterization of the as-cast samples}

The chemical composition of the as-cast samples is presented in Table 3. As observed, the chemical composition for all samples is within their nominal composition. In Fig. 1, the evolution of the density of the samples as a function of the molybdenum content is shown. As seen, the density of the alloys increases linearly with the amount of molybdenum because this element possesses a higher atomic weight $\left(10.23 \mathrm{~g} / \mathrm{cm}^{3}\right)$ when compared with titanium or zirconium (4.51 and $6.51 \mathrm{~g} /$ $\mathrm{cm}^{3}$, respectively).

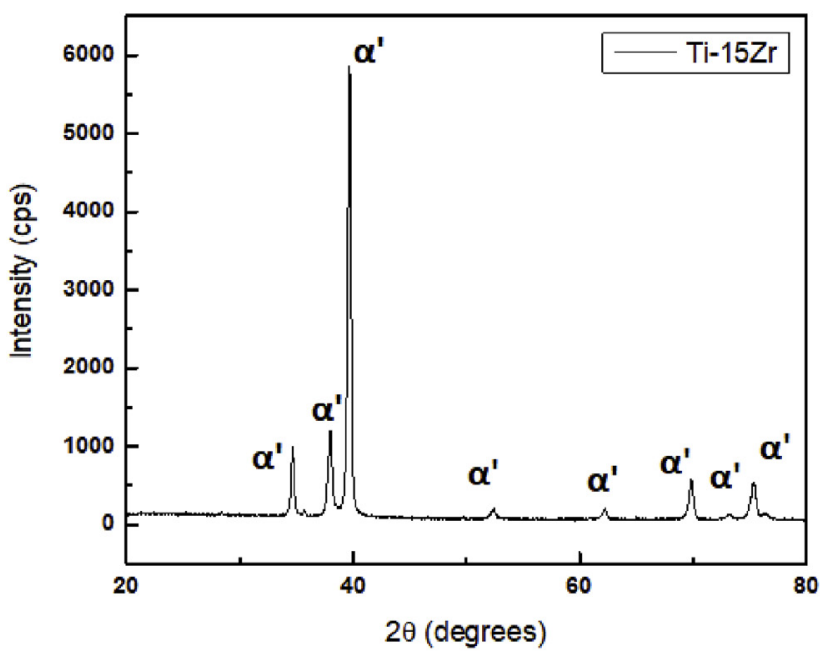

a)

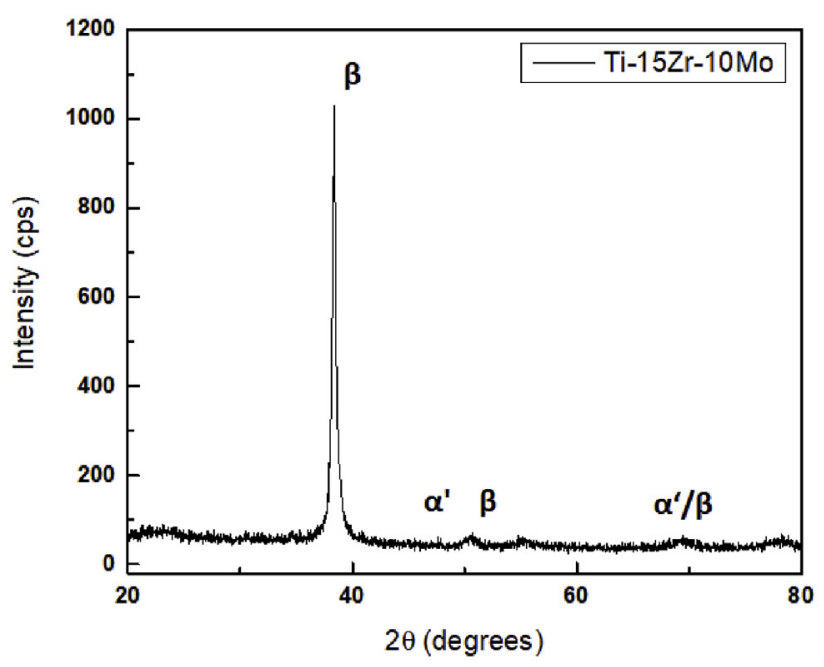

c)
Fig. 2 compares the as-cast Ti-15Zr-xMo system with others commercial alloys used for biomedical application. As it can be observed in the figure, the cast alloys presented density values in the same range of the Ti-15Mo (ASTM F2066). On the other hand, the studied alloys presented lower values when compared with those of the TNZT system (Ti-35Nb-5Ta and Ti-35Nb-5Ta-7Zr). Therefore, in terms of density, the Ti-15Zr-xMo system alloy is considered to be a good candidate to be a biomaterial, when compared to others Ti alloys.

Figs. 3 and 4 shows representative optical micrographs and SEM analysis of the as-cast alloys, respectively. While in Fig. 5, representative XRD spectra of those samples are presented.

The first remark is that all samples appear to be homogeneous, as no agglomeration or segregation of elements or phases were observed. Also, samples were found to be free of porosity.

Regarding the Ti-15Zr alloy (Figs. 3a and 4a), it is possible to observe a Widmanstatten-like microstructure identified by XRD as $\alpha^{\prime}$ phase (see Fig. 5a). The addition of $5 \mathrm{wt} \%$ of molybdenum (Ti$15 \mathrm{Zr}-5 \mathrm{Mo}$ alloy) resulted in the appearance of a $\beta$ phase matrix with

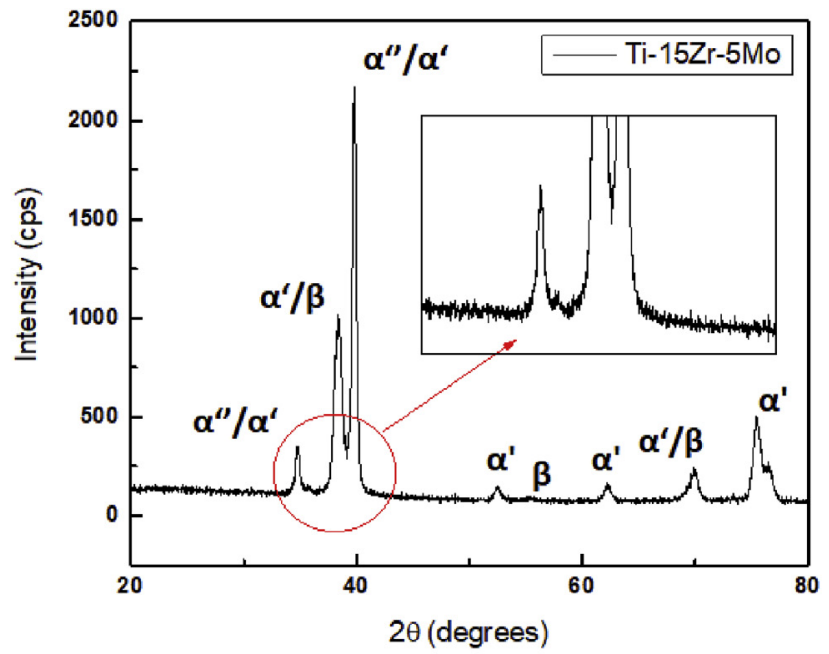

b)

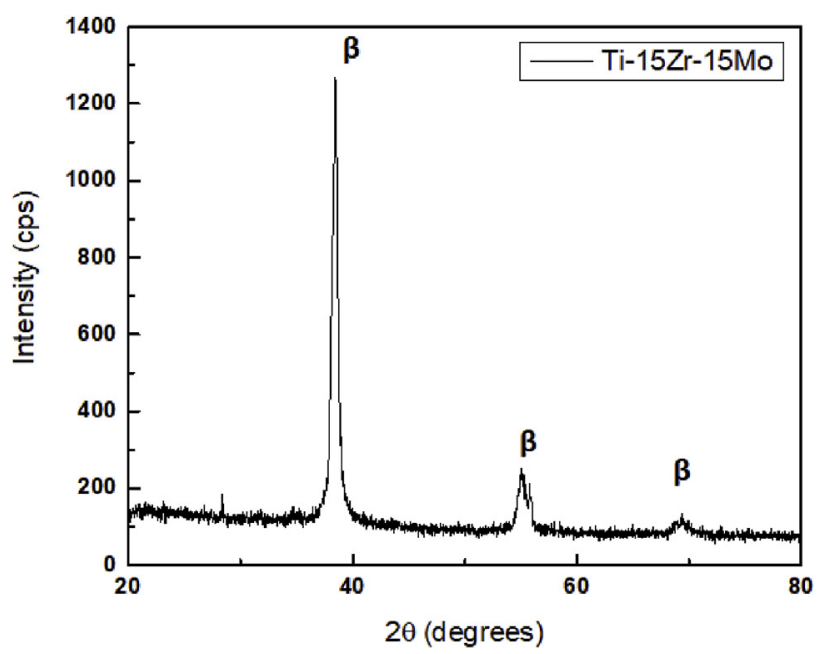

d)

Fig. 5. XRD of the as-cast Ti-15Zr-xMo alloys: a) Ti-15Zr; b) Ti-15Zr-5Mo; c) Ti-15Zr-10Mo; d) Ti-15Zr-15Mo. 


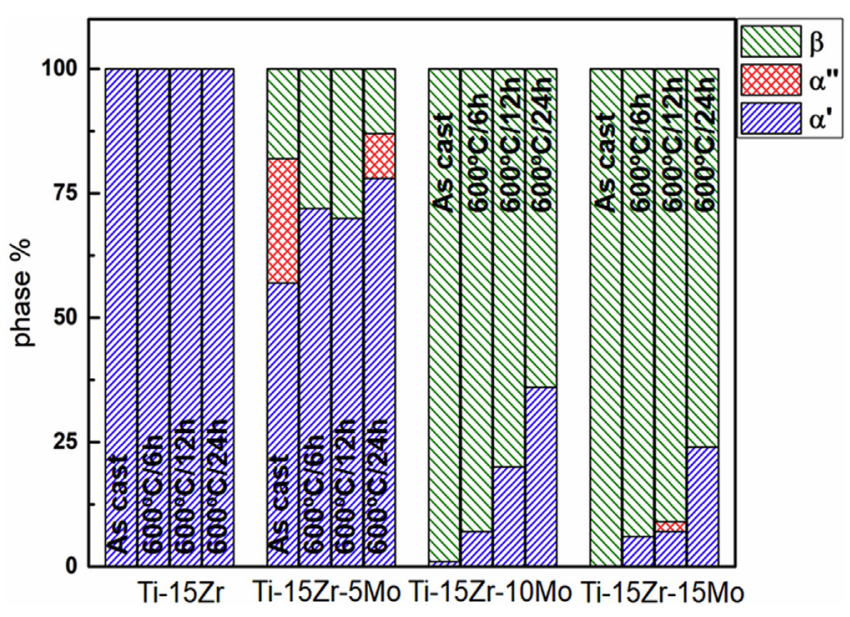

Fig. 6. Phase quantities of the $600{ }^{\circ} \mathrm{C}$ heat treatment conditions for the Ti15Zr-xMo alloys: a) Ti-15Zr; b) Ti-15Zr-5Mo; c) Ti-15Zr-10Mo and d) Ti-15Zr-15Mo.

fine needles of $\alpha^{\prime}$ phase at the grain boundaries (Figs. 3b, 4b and 5b). A further increase in the molybdenum amount (Ti-15Zr10Mo and Ti-15Zr-15Mo alloys) resulted in a fully $\beta$ structure (Figs. 3c, 4c and 5c, 3d, 4d and 5d).

\section{2. $600{ }^{\circ} \mathrm{C}$ heat treatments}

As referred, the heat treatments were carried out at $600{ }^{\circ} \mathrm{C}$ with holding times of $6 \mathrm{~h}, 12 \mathrm{~h}$ and $24 \mathrm{~h}$, with all samples being cooled at $10^{\circ} \mathrm{C} / \mathrm{min}^{-1}$. For the structural and microstructural analysis, optical micrographs, SEM and XRD spectra were obtained. The XRD and Rietveld results are summarized in Fig. 6 in terms of the phase percentage as a function of the amount of molybdenum and heat treatment conditions. Also, in Figs. 7 and 8, the evolution of the microhardness and hardness for each treatment as a function of the molybdenum content is presented.

As it can be observed in Fig. 6, for the Ti-15Zr and Ti-15Zr-5Mo alloys, no significant changes were observed in terms of phase constituents. The Ti-15Zr alloy remain with a fully $\alpha^{\prime}$ lamellar structure while the amount of $\beta$ phase keeps among $13 \%$ and $30 \%$ in the Ti-15Zr-5Mo alloy, with just a slight increase in the $\alpha^{\prime}$

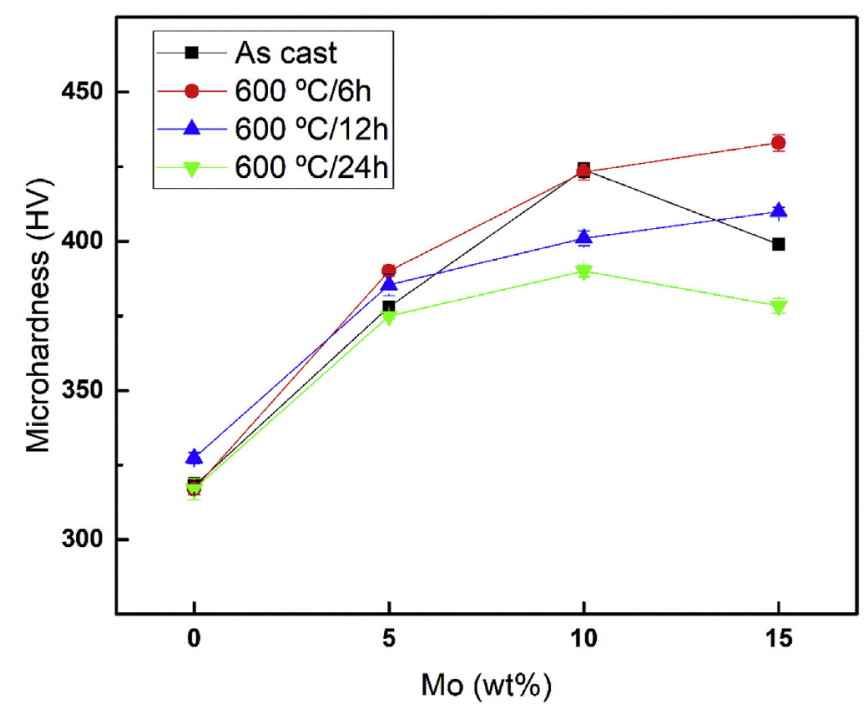

Fig. 7. Microhardness (HV) values of Ti- $15 \mathrm{Zr}-\mathrm{xMo}$ alloys for the $600{ }^{\circ} \mathrm{C}$ heat treatment conditions, compared with the as-cast alloys.

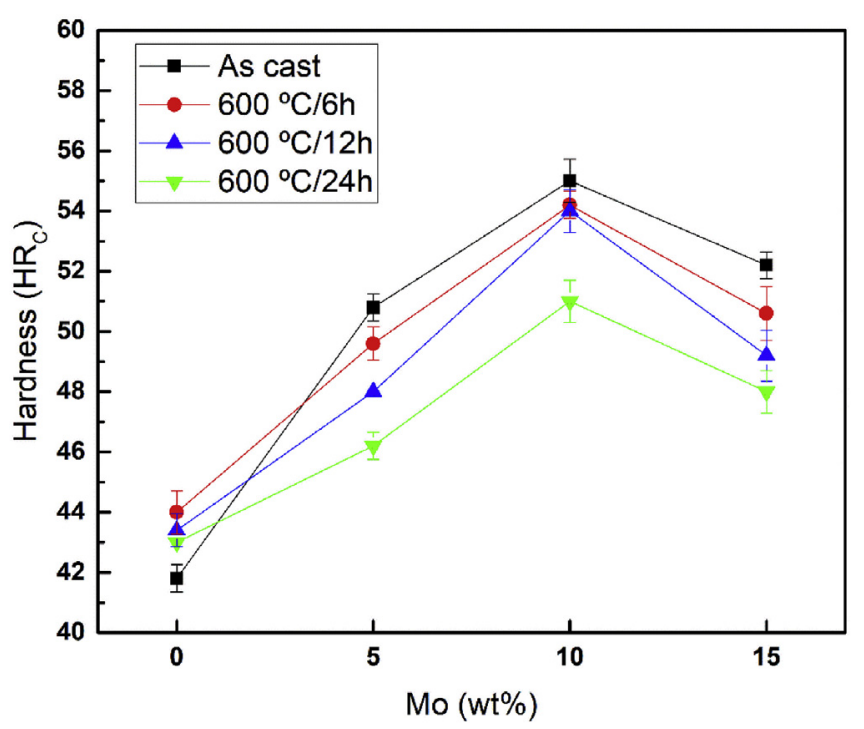

Fig. 8. Hardness $\left(\mathrm{HR}_{\mathrm{C}}\right)$ values of Ti-15Zr-xMo alloys for the $600{ }^{\circ} \mathrm{C}$ heat treatment conditions, compared with the as-cast alloys.

introduced by longer heat treatments. Therefore, no significant variations in the microhardness could be observed for these two alloys, as depicted from Fig. 7. In fact, the microhardness of the Ti$15 \mathrm{Zr}$ alloy is around 317 and $327 \mathrm{HV}_{250}$, while it is in the range 375 and $390 \mathrm{HV}_{250}$, for the Ti-15Zr-5Mo alloy.

Although the Ti-15Zr-10Mo (Figs. 3c and 4c) and Ti-15Zr-15Mo (Figs. 3d and 4d) as-cast alloys exhibited mainly $\beta$ phase (with just a small amount of $\alpha^{\prime}$ phase in the alloy containing $10 \mathrm{wt} \%$ of molybdenum) heat treatments allowed $\alpha^{\prime}$ phase nucleation and growth as summarized in Fig. 6. In Figs. 9-12 representative micrographs of the heat-treated samples as a function of the heat treatment time are presented for the Ti-15Zr-10Mo and Ti-15Zr15Mo, respectively. As observed in Figs. 9-12 an acicular structure becomes well apparent inside the $\beta$ phase grains. In fact, Rietveld analysis shows a significant increase in the $\alpha^{\prime}$ content introduced by the heat treatment time for the Ti-15Zr-10Mo alloy. However, for the Ti-15Zr-15Mo the increase of the $\alpha^{\prime}$ phase is less pronounced, although for longer heat treatments ( $24 \mathrm{~h}$ ) a relatively higher amount of $\alpha^{\prime}$ phase is observed. Also, for this alloy there is a small portion of $\alpha^{\prime \prime}$ phase for the $12 \mathrm{~h}$ heat treatment (Fig. 6d). Although this was not expected, its appearance might result from a small retention of this phase during the $\beta-\alpha$ transition. The consequences in terms of microhardness were therefore higher for these two alloys, as shown in Fig. 7, and discussed below.

In fact, analysis of Fig. 7 indicates that, in general, the hardness of the alloys increased with the molybdenum addition reflecting its beta stabilizer effect and solid solution hardening. For these two alloys, the hardness decreases with the increase of the heat treatment time, in accordance with the increase in the amount of $\alpha^{\prime}$ phase. As the heat treatment time increases the volume fraction of $\beta$ phase decreases accompanying the increase in the $\alpha^{\prime}$ phase of the alloy. Because of the lower packing factor for the acicular structure, the microhardness of the heat treated alloys decreases. Also, an effect of the thermal stress-relieving, arising from the processing of the samples may also contribute to the observed decrease in hardness. Anyhow, at $600{ }^{\circ} \mathrm{C}$ the time of treatment is apparently favoring the nucleation and growth of the $\alpha^{\prime}$ phase. Also, the Ti$15 \mathrm{Zr}-15 \mathrm{Mo}$ have shown greater microhardness compared with the other alloys for the $600^{\circ} \mathrm{C} / 6 \mathrm{~h}$ and $600^{\circ} \mathrm{C} / 12 \mathrm{~h}$ heat treatment conditions. Again, this event can be related with the $\beta$ phase content of the alloy, higher in the Ti-15Zr-15Mo, as shown in Fig. 6. 


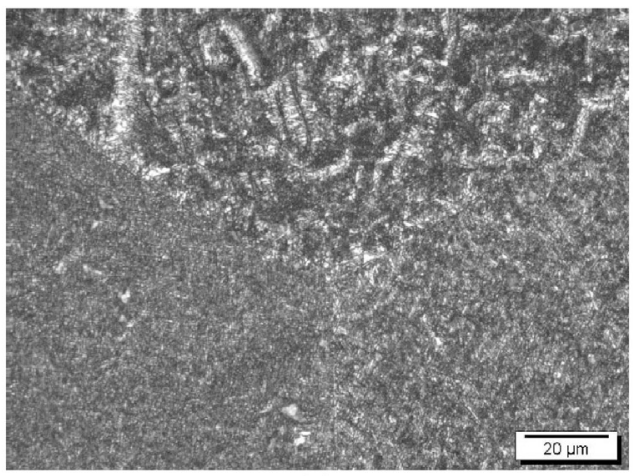

(a)

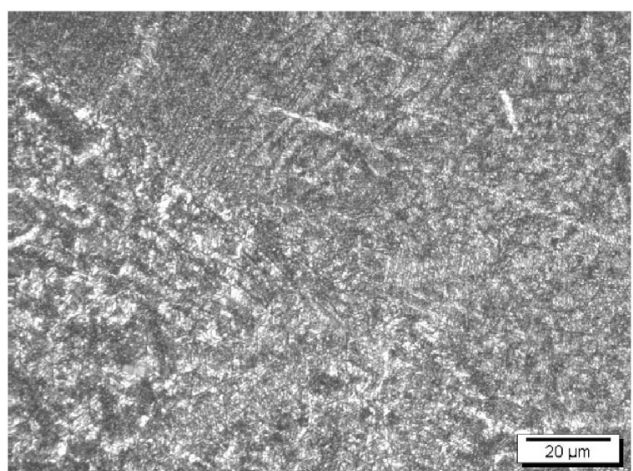

(b)

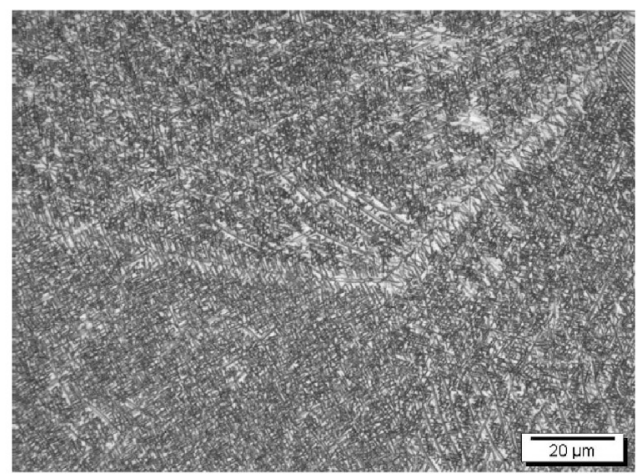

(c)

Fig. 9. Optical microscopy of the Ti-15Zr-10Mo heat treated alloy: (a) $600^{\circ} \mathrm{C} / 6 \mathrm{~h}$; (b) $600^{\circ} \mathrm{C} / 12 \mathrm{~h}$; (c) $600^{\circ} \mathrm{C} / 24 \mathrm{~h}$.

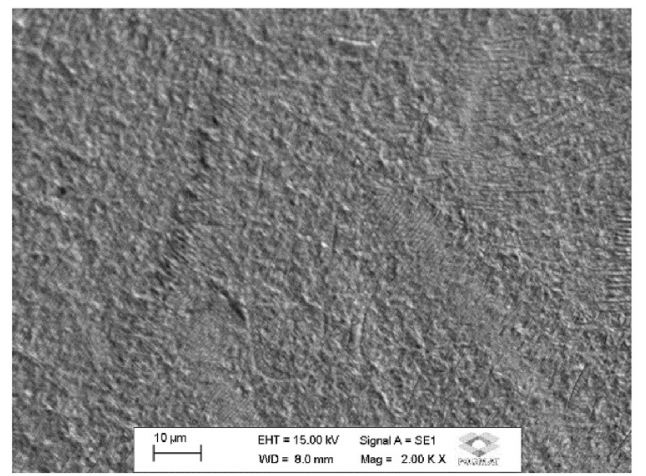

(a)

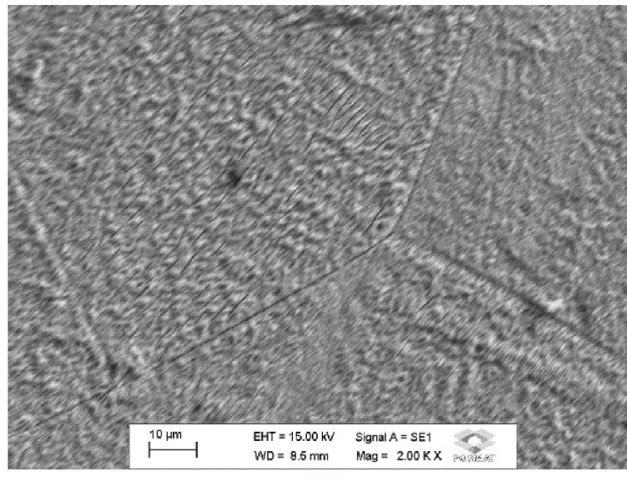

(b)

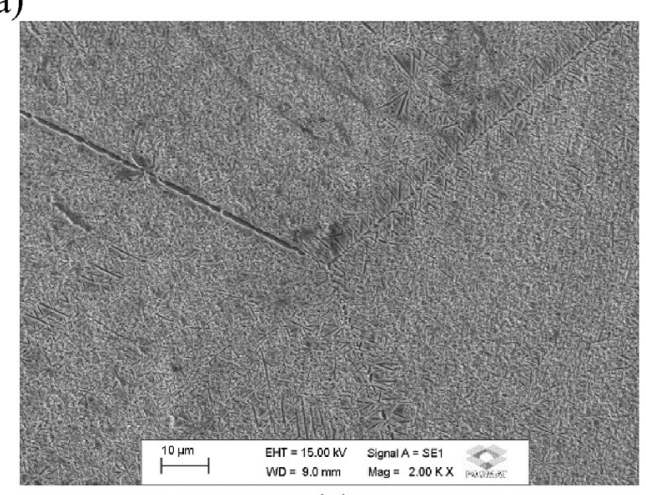

(c)

Fig. 10. SEM analysis of the Ti-15Zr-10Mo heat treated alloy: (a) $600^{\circ} \mathrm{C} / 6 \mathrm{~h}$; (b) $600^{\circ} \mathrm{C} / 12 \mathrm{~h}$; (c) $600^{\circ} \mathrm{C} / 24 \mathrm{~h}$. 


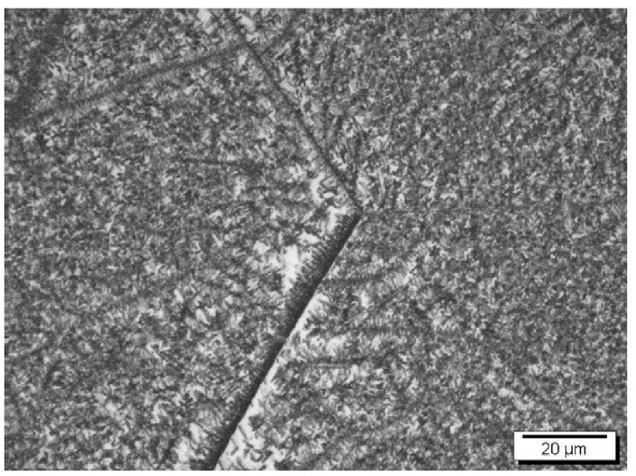

(a)

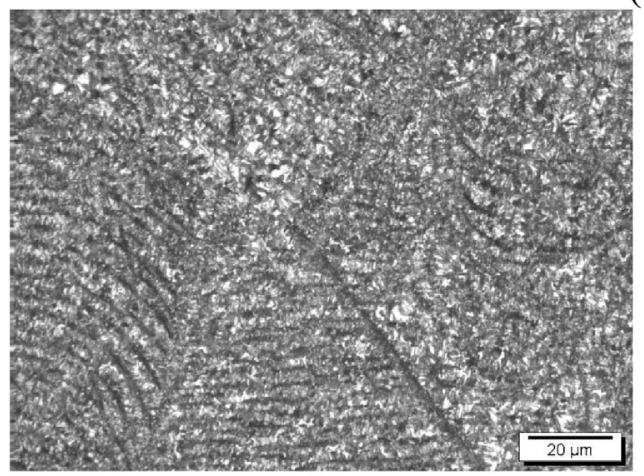

(b)

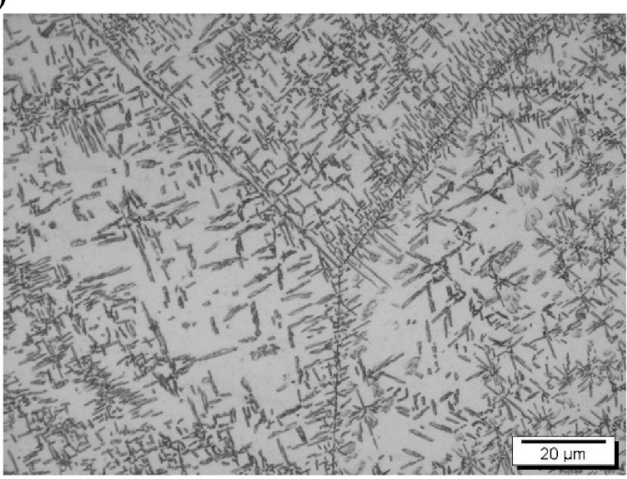

(c)

Fig. 11. Optical Microscopy of the Ti-15Zr-15Mo heat treated alloy: (a) $600^{\circ} \mathrm{C} / 6 \mathrm{~h}$; (b) $600^{\circ} \mathrm{C} / 12 \mathrm{~h}$; (c) $600^{\circ} \mathrm{C} / 24 \mathrm{~h}$.

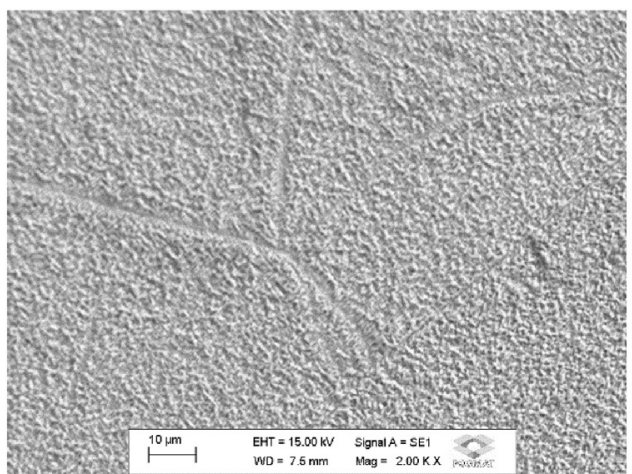

(a)

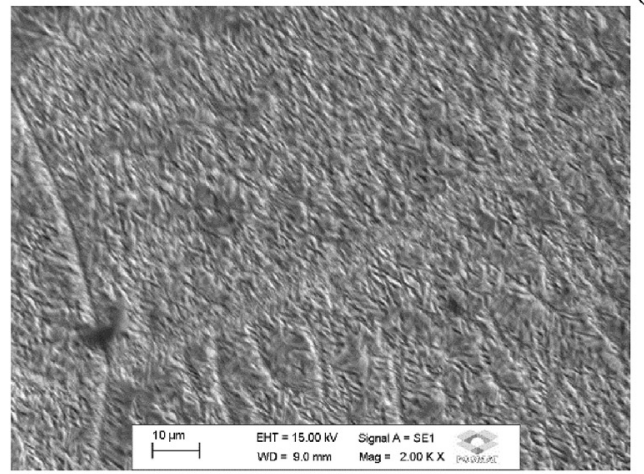

(b)

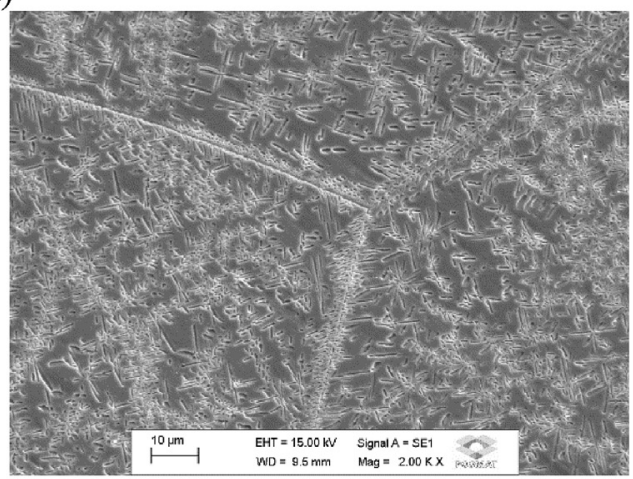

(c)

Fig. 12. SEM analysis of the Ti- $15 \mathrm{Zr}-15 \mathrm{Mo}$ heat treated alloy: (a) $600^{\circ} \mathrm{C} / 6 \mathrm{~h}$; (b) $600^{\circ} \mathrm{C} / 12 \mathrm{~h}$; (c) $600^{\circ} \mathrm{C} / 24 \mathrm{~h}$. 


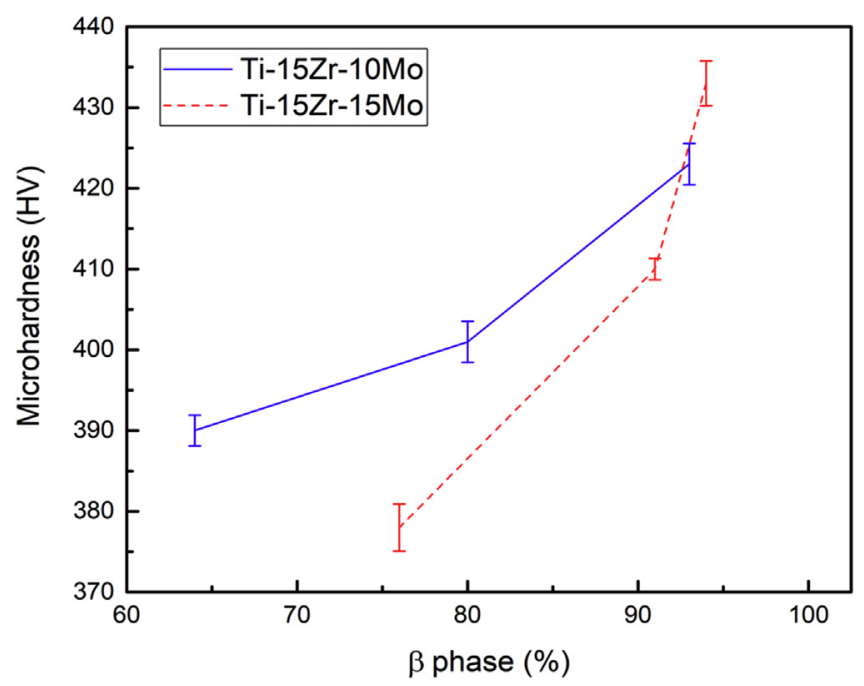

Fig. 13. Correlation between $\beta$ phase amount and microhardness evolution for the Ti15Zr-10Mo and Ti-15Zr-15Mo heat-treated alloys.

From Fig. 8, where the Hardness $\left(\mathrm{HR}_{\mathrm{C}}\right)$ of the conditions are presented, it's possible to observe the same behavior, where the hardness increased with the molybdenum addition and decreased with the rise in the heat treatment time. In agreement with the nucleation and growth of the acicular $\alpha^{\prime}$ phase in the alloy.

Regarding Ti-15Zr-10Mo alloy, it presented the higher value of microhardness in the as-cast condition, as shown in Fig. 7. This could be related with the fact that the Ti-15Zr-10Mo is known to be prone to form small amounts of $\omega$ phase (a hard phase that introduces brittleness), which is not detected by XRD, but only by transmission electron microscopy [16]. The heat treatments carried out at $600{ }^{\circ} \mathrm{C}$ could be responsible for the suppression of the $\omega$ phase. In fact, some studies suggest that in Ti-based alloys the $\omega$ phase can act as a nucleation site for the $\alpha^{\prime}$ phase, leading to a fine and dispersed acicular structure at the $\beta-\omega$ interface. Consequently, there is a decrease in hardness as a function of the duration in the heat treatment as the $\omega$ phase starts to disappear [17,18] [19,20]. Nevertheless, as shown in Fig. 13 that correlates the microhardness as a function of the amount of $\beta$ phase, the decrease in hardness attributed to the formation of the $\alpha^{\prime}$ phase (i.e. less $\beta$ phase), is much less pronounced in Ti-15Zr-10Mo alloy, when compared to Ti$15 \mathrm{Zr}-15 \mathrm{Mo}$ alloy, which might indicate that the $\omega$ phase is still present. Further work will be carried out in order to investigate in more detail these softening mechanisms.

\section{Conclusions}

In this paper, a first insight on the effect of relatively low temperature heat treatments $\left(600{ }^{\circ} \mathrm{C}\right)$ on the microstructure and microhardness of Ti-15Zr-xMo alloys was made. The main conclusions are:

- The molybdenum presented a beta stabilizer behavior and the as-cast alloys exhibited microstructures with $\alpha^{\prime}, \alpha^{\prime}+\beta$ and $\beta$ phases, as the amount of molybdenum was increased;

- However, heat treatments performed at $600{ }^{\circ} \mathrm{C}$ in the $\beta$ alloys induced the nucleation and growth of the $\alpha^{\prime}$ phase, which was more pronounced in the alloy containing $10 \%$ of molybdenum;

- Nevertheless, the decrease in hardness due to the formation of the $\alpha^{\prime}$ phase is less steep in the $10 \%$ of molybdenum alloy suggesting some eventual influence of the $\omega$ phase, which should be investigated in more detail in further studies.

\section{Acknowledgements}

The authors thanks Brazilian agencies Capes (grant \#99999.008666/2014-08), CNPq (grants \#490761/2013-5, \#481313/2012-5 and \#307.279/2013-8) and FAPESP (grant \#2010/ 20440-7) for their financial support. Also, thanks the colleague Pedro A. B. Kuroda for the helping hand along this work.

\section{References}

[1] M. Geetha, A.K. Singh, R. Asokamani, A.K. Gogia, Ti based biomaterials, the ultimate choice for orthopaedic implants-a review, Prog. Mater. Sci. 54 (3) (2009) 397-425, http://dx.doi.org/10.1016/j.pmatsci.2008.06.004.

[2] Y. Li, C. Yang, H. Zhao, S. Qu, X. Li, Y. Li, New developments of Ti-based alloys for biomedical applications, Materials 7 (3) (2014) 1709-1800, http:// dx.doi.org/10.3390/ma7031709.

[3] D.R.N. Correa, F.B. Vicente, R.O. Araújo, M.L. Lourenço, P.A.B. Kuroda, M.A.R. Buzalaf, C.R. Grandini, Effect of the substitutional elements on the microstructure of the Ti-15Mo-Zr and Ti-15Zr-Mo systems alloys, J. Mater. Res. Technol. 4 (2) (2015) 180-185, http://dx.doi.org/10.1016/j.jmrt.2015.02.007.

[4] C. Leyens, M. Peters, Titanium and Titanium Alloys: Fundamentals and Applications, John Wiley \& Sons, 2003.

[5] D. Banerjee, J.C. Williams, Perspectives on titanium science and technology, Acta Mater. 61 (3) (2013) 844-879, http://dx.doi.org/10.1016/ j.actamat.2012.10.043.

[6] G. Lütjering, J.C. Williams, Titanium, vol. 2, Springer, Berlin, 2003.

[7] A. Pathak, S. Banumathy, R. Sankarasubramanian, A.K. Singh, Orthorhombic martensitic phase in Ti-Nb alloys: a first principles study, Comput. Mater. Sci. 83 (2014) 222-228, http://dx.doi.org/10.1016/j.commatsci.2013.10.035.

[8] S. Banumathy, R.K. Mandal, A.K. Singh, Structure of orthorhombic martensitic phase in binary Ti-Nb alloys, J. Appl. Phys. 106 (9) (2009) 093518, http:// dx.doi.org/10.1063/1.3255966.

[9] W.F. Ho, S.C. Wu, S.K. Hsu, Y.C. Li, H.C. Hsu, Effects of molybdenum content on the structure and mechanical properties of as-cast Ti-10Zr-based alloys for biomedical applications, Mater. Sci. Eng. C 32 (3) (2012) 517-522, http:// dx.doi.org/10.1016/j.msec.2011.12.003.

[10] F.B. Vicente, D. Correa, T.A. Donato, V.E. Arana-Chavez, M.A. Buzalaf, C.R. Grandini, The influence of small quantities of oxygen in the structure, microstructure, hardness, elasticity modulus and cytocompatibility of Ti-Zr alloys for dental applications, Materials 7 (1) (2014) 542-553, http:// dx.doi.org/10.3390/ma7010542.

[11] Y. Shi, G. Zhang, M. Li, D. Guo, Z. Zhang, B. Wei, ..., X. Zhang, Effect of heat treatment on the microstructure and tensile properties of deformed $\alpha / \beta$ Ti-47Zr-5Al-3V alloy, J. Alloys Compd. 665 (2016) 1-6, http://dx.doi.org/ 10.1016/j.jallcom.2016.01.023.

[12] D. Qin, Y. Lu, D. Guo, L. Zheng, Q. Liu, L. Zhou, On preparation of bimodal Ti-5Al-5V-5Mo-3Cr-0.4 Si (Ti-5553s) alloy: $\alpha+\beta$ forging and heat treatment, Mater. Sci. Eng. A 609 (2014) 42-52, http://dx.doi.org/10.1016/ j.msea.2014.04.056.

[13] S.Q. Wu, Y.J. Lu, Y.L. Gan, T.T. Huang, C.Q. Zhao, J.J. Lin, ..., J.X. Lin, Microstructural evolution and microhardness of a selective-laser-melted Ti-6Al-4V alloy after post heat treatments, J. Alloys Compd. 672 (2016) 643-652, http://dx.doi.org/10.1016/j.jallcom.2016.02.183.

[14] Y. Chen, Z. Du, S. Xiao, L. Xu, J. Tian, Effect of aging heat treatment on microstructure and tensile properties of a new $\beta$ high strength titanium alloy, J. Alloys Compd. 586 (2014) 588-592, http://dx.doi.org/10.1016/ j.jallcom.2013.10.096.

[15] D.R.N. Correa, P.A.B. Kuroda, C.R. Grandini, Structure, microstructure, and selected mechanical properties of Ti-Zr-Mo alloys for biomedical applications, Adv. Mater. Res. 922 (2014) 75-80. Trans Tech Publications.

[16] D.R.N. Correa, P.A.B. Kuroda, C.R. Grandini, L.A. Rocha, F.G.M. Oliveira, A.C. Alves, F. Toptan, Tribocorrosion behavior of $\beta$-type Ti-15Zr-based alloys, Mater. Lett. 179 (C) (2016) 118-121, http://dx.doi.org/10.1016/ j.matlet.2016.05.045.

[17] S.B. Gabriel, L.H. de Almeida, C.A. Nunes, J. Dille, G.A. Soares, Maximisation of the ratio of microhardness to the Young's modulus of Ti-12Mo-13Nb alloy through microstructure changes, Mater. Sci. Eng. C 33 (6) (2013) 3319-3324, http://dx.doi.org/10.1016/j.msec.2013.04.015.

[18] F. Prima, P. Vermaut, G. Texier, D. Ansel, T. Gloriant, Evidence of $\alpha$-nanophase heterogeneous nucleation from $\omega$ particles in a $\beta$-metastable Ti-based alloy by high-resolution electron microscopy, Scr. Mater. 54 (4) (2006) 645-648, http://dx.doi.org/10.1016/j.scriptamat.2005.10.024.

[19] W.F. Ho, A comparison of tensile properties and corrosion behavior of cast Ti-7.5 Mo with cp Ti, Ti-15Mo and Ti-6Al-4V alloys, J. Alloys Compd. 464 (1) (2008) 580-583, http://dx.doi.org/10.1016/j.jallcom.2007.10.054.

[20] X.H. Min, S. Emura, L. Zhang, K. Tsuzaki, Effect of Fe and $\mathrm{Zr}$ additions on $\omega$ phase formation in $\beta$-type Ti-Mo alloys, Mater. Sci. Eng. A 497 (1) (2008) 74-78, http://dx.doi.org/10.1016/j.msea.2008.06.018. 